\title{
Quantitative Studies of Science in Germany
}

Guest Editors:

\author{
Clemens Blümel and Stephan Gauch
}

